\title{
Experimental and chemical kinetic study of silicon nitride via LPCVD at low temperature from disilane and ammonia
}

\author{
R. HENDA, E. SCHEID, L.K. KOUASSI, J. SAMITIER* ${ }^{*}$ and A. EL HASSANI* \\ LAAS-CNRS, 7 avenue du Colonel Roche, 31077 Toulouse cedex, France \\ " LCMM-DFAE, Universitat de Barcelona, Av. Diagonal, 645 Barcelona, Spain
}

\begin{abstract}
Silicon nitride was deposited from disilane and ammonia reactant gases under LPCVD conditions and at temperatures around $600{ }^{\circ} \mathrm{C}$. The growth rate was studied experimentally on 4 and 5 -inch silicon wafers by batch depositions in a horizontal hotwall LPCVD furnace. The kinetics of growth was found to follow a LangmuirHinshelwood mechanism and the appropriate kinetic constants were estimated using the experimental data. The theoretical results expressed in terms of deposition rate are compared with the experimental data and they are in good agreement. The film properties were assessed by ellipsometry and their composition was determined by FT-IR spectroscopy. Refractive index at $830.0 \mathrm{~nm}$ was correlated with the film composition $\mathrm{Si} / \mathrm{N}$ and nitrogen concentration (in atom $\mathrm{cm}^{-3}$ ). These correlations show a linear dependency of the refractive index on the composition and on the amount of nitrogen supplied to the deposited layers.
\end{abstract}

\section{INTRODUCTION}

Considerable interest has been expressed in the study of chemical vapor deposition of silicon nitride films and their applications in several electronic devices like thin-film transistors (TFTs), which are used as switching arrays in liquid crystal displays [1]. It has also been reported that silicon nitride masks against the oxidation of silicon. When low temperature process is needed, Plasma-enhanced CVD (PECVD) is generally used. However, this method presents a great disadvantage which is the large amount of electrical defects in the grown films. In addition, this technique is expensive and not suited for mass production.

In this paper, silicon nitride elaborated by LPCVD is investigated with a particular attention paid to disilane ( $\mathrm{Si}_{2} \mathrm{H}_{6}$ or DS) as a silicon source gas. The reason is that this silicon hydride is less stable than silane $\left(\mathrm{SiH}_{4}\right)$ or dichlorosilane $\left(\mathrm{SiH}_{2} \mathrm{Cl}_{2}\right)$ and hence, higher deposition 
rates can be expected at temperatures around $600^{\circ} \mathrm{C}$. Indeed, it is known that it is difficult to obtain sizeable LPCVD deposition rates of silicon nitride when reducing the temperature of the process below $700^{\circ} \mathrm{C}$ if $\mathrm{SiH}_{2} \mathrm{Cl}_{2}$ or $\mathrm{SiH}_{4}$ are used. Furthermore, we have noticed in a previous study [2] that $\mathrm{NH}_{3}$ strongly inhibits the adsorption of $\mathrm{SiH}_{4}$, leading to a very low growth rate.

In consequence, the $\mathrm{Si}_{2} \mathrm{H}_{6}-\mathrm{NH}_{3}$ system has been studied in order to overcome these drawbacks.

\section{EXPERIMENTAL DETAIIS}

Silicon nitride was deposited in a horizontal hot-wall LPCVD furnace using a batch of 15 wafers of 10 and $12.5 \mathrm{~cm}$ diameter. The wafers were normal to the main flow of the gases, which were injected through the door of furnace. Disilane (or DS) and ammonia $\left(\mathrm{NH}_{3}\right)$ were used as source gases. The interwafer spacing was mainly set at $10 \mathrm{~mm}$. Deposition temperatures ranging from 555 to $645^{\circ} \mathrm{C}$ were used. They were maintained with an accuracy of $\pm 1 / 2{ }^{\circ} \mathrm{C}$ over the deposition zone using a platinum/platinum-rhodium thermocouple. The total pressure was measured with a BARATRON gauge (MKS, ref. 122A) and varied in the range 0.06-0.25 Torr with an accuracy of 0.002 Torr.

The film thicknesses and refractive index were monitored with a three-wavelength ellipsometer in order to evaluate their homogeneity on wafer and along the load. The $830.0 \mathrm{~nm}$ wavelength was mainly used because the deposited films are not absorbing in the near IR, even if they are silicon rich. The film composition ( $\mathrm{Si} / \mathrm{N}$ ratio and absolute nitrogen concentration [N]) was determined by FT-IR spectroscopy.

\section{RESULTS AND COMMENTS}

- $\mathrm{SiH}_{4}-\mathrm{NH}_{3}$ experiments:

Silicon nitride elaboration from silane and ammonia was the first LPCVD process used in industry [3], but it was quickly abandoned because of the unsatisfactory deposit homogeneity on wafer in the temperature range $800-900^{\circ} \mathrm{C}$. In a previous study [2], we reported the results we obtained at a low temperature $\left(600^{\circ} \mathrm{C}\right)$. The experiments performed at such a temperature also showed a high nonuniformity of the film thickness and refractive index with, in addition, a small deposition rate at the center of the wafer (about $2 \dot{\mathrm{A}} \mathrm{min}^{-1}$ ). However, for the same partial pressure of $\mathrm{SiH}_{4}$, an uniform deposition rate of $40 \AA \mathrm{min}^{-1}$ is obtained over the wafer when silane is diluted in nitrogen used as an inert gas. This phenomenon is probably due to the inhibition of the silane adsorption by ammonia, as we can see in the following.

In order to depict the $\mathrm{SiH}_{4}-\mathrm{NH}_{3}$ system features, we carried out two runs at the same operating conditions except the distance between the front door and the first wafer of the load. In the first run, the load was shifted $15 \mathrm{~cm}$ before the tube center, and in the second run, it was shifted $30 \mathrm{~cm}$ downstream the reactor from the furnace center. The results show that the deposition rate of the second run is 2.5 times the one of the first run. This may be explained by the 
production of silylene $\left(\mathrm{SiH}_{2}\right)$ in the gas phase before the wafer tray. This silylene production should increase with the load-front door distance and thus, should result in the increase of the film growth rate. Moreover, this fact matches with the inhibition of silane adsorption by ammonia, so that the deposition of silicon can occur only through the $\mathrm{SiH}_{2}$ produced in the gas phase. This is in accordance with the high refractive index values of the films providing from the second run, which indicates a higher silicon content. Thus, in the light of the results above, there is no interest to use $\mathrm{SiH}_{4}$ for the deposition of silicon nitride around $600^{\circ} \mathrm{C}$. However, disilane would be of a great use because its pyrolysis can give much higher $\mathrm{SiH}_{2}$ concentration.

$-\mathrm{Si}_{2} \mathrm{H}_{6}-\mathrm{NH}_{3}$ experiments:

The main results obtained for different operating conditions are listed in Table 1. We note that the increase of the process temperature, with all the other operating conditions maintained constant, leads to an increase of the deposition rate only at low pressure (compare runs $n^{\circ} 1$ and 2 to runs $n^{\circ} 8$ and 3 , respectively). At high total pressure, a clear decrease of the deposition rate occurs with increasing the temperature. This phenomenon might be explained by considering the pressure dependence of the kinetic constants of disilane pyrolysis in the gas phase $[4,5,6]$. Indeed, according to Scheid et al. [6], at a given temperature of deposition, the kinetic constant of the forward disilane pyrolysis reaction is proportional to the total pressure.

Table 1: Operating conditions and experimental deposition rate.

Td: temperature of deposition, P: pressure of deposition, QDS and QNH3 :flow rates of gases, rexp: growth rate value measured at the center of the wafer.

\begin{tabular}{|c|l|c|c|c|c|}
\hline Run $\mathrm{n}^{\circ}$ & Td( $\left.{ }^{\circ} \mathrm{C}\right)$ & $\begin{array}{c}\text { QDS } \\
(\mathrm{sccm})\end{array}$ & $\begin{array}{c}\text { QNH3 } \\
\text { (sccm) }\end{array}$ & $\begin{array}{c}\mathrm{p} \\
\text { (mTorr) }\end{array}$ & $\begin{array}{c}\text { rexp( } \mathrm{A} / \mathrm{min}) \text { at the } \\
\text { wafer center }\end{array}$ \\
\hline 1 & 645 & 10.0 & 196.0 & 215 & 11.02 \\
2 & 645 & 4.0 & 12.0 & 64 & 18.54 \\
3 & 600 & 3.6 & 12.0 & 67 & 12.00 \\
4 & 600 & 4.0 & 60.0 & 125 & 10.37 \\
5 & 600 & 2.0 & 40.0 & 102 & 5.03 \\
6 & 600 & 2.0 & 100.0 & 150 & 6.15 \\
7 & 600 & 2.0 & 196.0 & 212 & 5.16 \\
8 & 600 & 10.0 & 196.0 & 215 & 18.60 \\
9 & 600 & 5.0 & 196.0 & 209 & 10.27 \\
10 & 600 & 4.0 & 140.0 & 176 & 9.44 \\
11 & 600 & 5.0 & 10.0 & 73 & 16.65 \\
12 & 600 & 5.0 & 10.0 & 70 & 17.76 \\
13 & 580 & 2.0 & 100.0 & 155 & 4.62 \\
14 & 555 & 2.0 & 100.0 & 148 & 3.09 \\
15 & 555 & 2.0 & 180.0 & 208 & 3.35 \\
\hline
\end{tabular}

This would mean that, at elevated total pressure, the disilane decomposition into silylene and silane becomes much important. So, taking into account both effects of deposition pressure and temperature the quantity of produced silylene is increased until a certain value of temperature where its consumption on the tube walls before the first wafer of the load overcomes its production leading to a smaller deposition rate along the wafer tray. We also 
noticed that the inhibition effect of ammonia on the deposition rate occurs only at higher process temperature $\left(>555^{\circ} \mathrm{C}\right)$. This might be due to the increase of $\mathrm{SiH}_{4}$ concentration in the gas phase, which however, can not adsorb on the surface because of its inhibition by $\mathrm{NH}_{3}$.

The crucial problem we encountred in the process of deposition of silicon nitride from the $\mathrm{Si}_{2} \mathrm{H}_{6}-\mathrm{NH}_{3}$ system was the noticeable nonuniformity of the film thickness along the wafers. Figure 1 illustrates a typical example of thickness and refractive index profiles along a wafer and shows a thickness nonuniformity ratio of $32 \%$ (i.e, the maximum film thickness on the wafer is 32 percent higher than the minimum one). This is obviously due to the variation of the silylene concentration in the interwafer zone, as it will be seen further. In an attempt to reduce this effect we proceeded at low pressure and obtained an acceptable improvement of the thickness uniformity which is only $19 \%$ as seen from the same figure (Fig. 1) but still far to be good from industrial viewpoint.

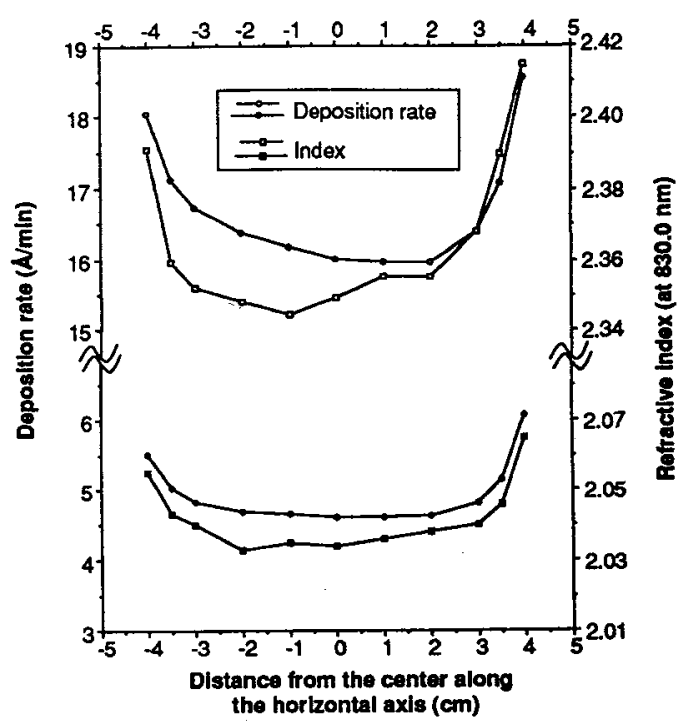

Figure 1: Thickness and refractive index along a wafer.

Upper curves: $\mathrm{T}=600^{\circ} \mathrm{C}, \mathrm{P}=150 \mathrm{mTorr}, \mathrm{Q}(\mathrm{DS})=2 \mathrm{sccm}, \mathrm{Q}\left(\mathrm{NH}_{3}\right)=100 \mathrm{sccm}$.

Lower curves: $\left.\mathrm{T}=600^{\circ} \mathrm{C}, \mathrm{P}=73 \mathrm{mTorr}, \mathrm{Q(DS}\right)=5 \mathrm{sccm}, \mathrm{Q}\left(\mathrm{NH}_{3}\right)=10 \mathrm{sccm}$.

In the same context, the best solution we expected to be reliable was to try to reduce the distance between wafer edge and tube walls. Indeed, this should lead to an increasing of the gas velocity and a better circulation of the active species in the interwafer zone. In that sense, we undertook some experiments using 5-inch wafers. Figure 2 represents a thickness profile along a 5-inch wafer compared to the one along a 4-inch wafer at the same operating conditions. So, it is easy to notice the great difference between the two profiles and the remarkable improvement of the thickness uniformity when 5-inch wafers are used $9.9 \%$ in the case of Fig.2). Other experiments done at a temperature of deposition of $645^{\circ} \mathrm{C}$ and under low pressure have presented a good thickness uniformity (less than $10 \%$ ) along the 5 -inch wafer. 


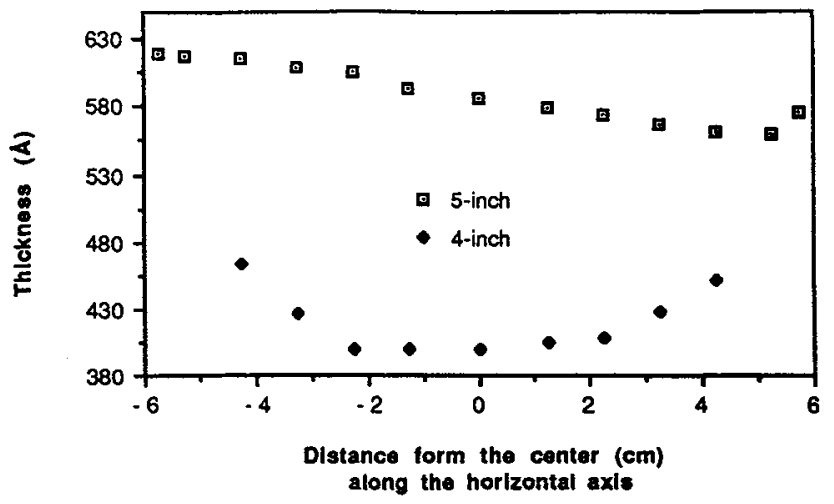

Figure 2: Thickness profile on a 4 and 5-inch wafers. $\mathrm{T}=600^{\circ} \mathrm{C}, \mathrm{P}=73 \mathrm{mTorr}, \mathrm{Q}(\mathrm{DS})=5 \mathrm{sccm}, \mathrm{Q}\left(\mathrm{NH}_{3}\right)=10 \mathrm{sccm}$.

-Composition vs. refractive index correlations of silicon nitride prepared from the $\mathrm{Si}_{2} \mathrm{H}_{6}-\mathrm{NH}_{3}$ system:

The silicon nitride films were characterised by Fourier transform IR spectroscopy and their refractive indices were systematically assessed by ellipsometry at $830.0 \mathrm{~nm}$. The FT-IR measurements allowed us to determine the film composition $\mathrm{Si} / \mathrm{N}$, where $\mathrm{Si}$ and $\mathrm{N}$ are the numbers of silicon and nitrogen atoms in the grown material, respectively, as well as the nitrogen concentration $[\mathrm{N}]$ (in atom $\mathrm{cm}^{-3}$ ) in the bulk of the film. In Figure 3, the absolute Si/N ratio and nitrogen concentration as measured by FT-IR are given as a function of the refractive index $\mathrm{n}$ at $830.0 \mathrm{~nm}$. The refractive index values appear to vary linearly with the composition of the layers and the concentration of nitrogen and can be expressed in the experimental range under discussion, i.e such that $2.0 \leq \mathrm{n} \leq 2.5$, as

$$
\begin{aligned}
& \mathrm{n}=0.813 \mathrm{Si} / \mathrm{N}+1.397 \\
& \mathrm{n}=-0.21110^{-22}[\mathrm{~N}]+3.065
\end{aligned}
$$

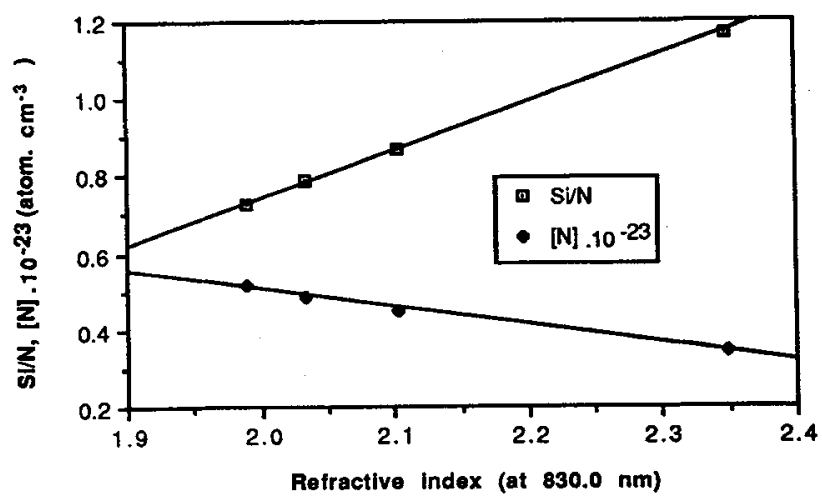

Figure 3: Composition and nitrogen concentration as a function of the film refractive index. 
The calculated numbers of silicon and nitrogen atoms into the deposited films per unit wafer area as a function of radial position are shown in Figure 4. The large amount of silicon atoms near the wafer edge reflects very well the thickness nonuniformity.

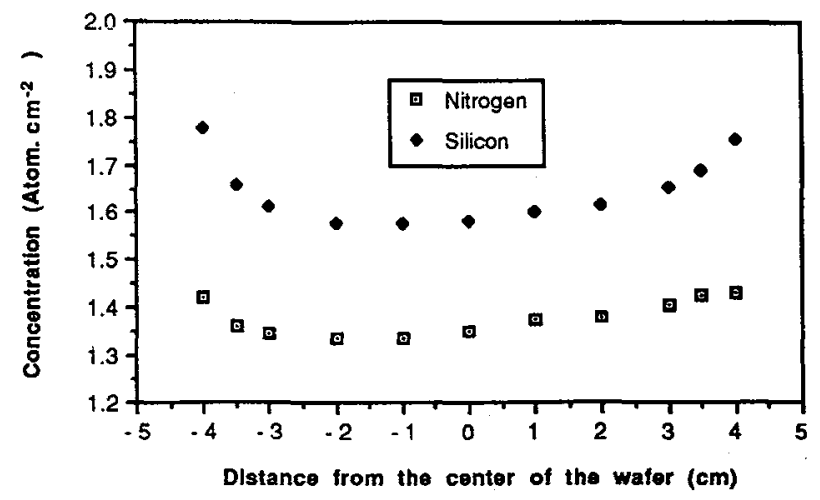

Figure 4: The silicon and nitrogen amounts supplied to a deposited film on a wafer. $T=600^{\circ} \mathrm{C}, P=73 \mathrm{mTorr}, \mathrm{Q}(\mathrm{DS})=5 \mathrm{sccm}, \mathrm{Q}\left(\mathrm{NH}_{3}\right)=10 \mathrm{sccm}$.

-Kinetic model:

The surface reaction kinetic model of the silicon nitride-LPCVD has been investigated by means of an analytical/numerical model. This analytical model was first proposed by J.-T. Wang et al. [7] for the case of $\mathrm{SiH}_{2} \mathrm{Cl}_{2}-\mathrm{NH}_{3}$ system assuming that the deposited films are stoichiometric. In the case of the $\mathrm{Si}_{2} \mathrm{H}_{6}-\mathrm{NH}_{3}$ system, this model has been modified and extended for non-stoichiometric films as well, by using the correlations given in the section above, i.e Eq. (1) and (2), and taking into account the depletion effect of the reactants along the furnace and the wafers load.

The kinetics of growth has been found to follow a Langmuir-Hinshelwood mechanism expressed in terms of the deposition rate as

$$
r_{c}=\frac{k_{S} P_{D S} P_{N H 3}}{\left(1+k_{D S} P_{D S}\right)\left(1+k_{N H 3} P_{N H 3}\right)}
$$

Where $\mathrm{P}_{\mathrm{NH} 3}$ and $\mathrm{P}_{\mathrm{DS}}$ are the partial pressures of ammonia and disilane respectively, and $\mathrm{k}_{\mathrm{s}}$, $k_{\mathrm{NH} 3}$ and $k_{\mathrm{DS}}$ the kinetic constants.

The mechanism corresponding to the kinetic model above would mean that the interaction on the solid surfaces takes place between the two chemisorbed reactants, i.e $\mathrm{Si}_{2} \mathrm{H}_{6}$ and $\mathrm{NH}_{3}$, on different active sites. The following kinetic constants $k_{s}, k_{\mathrm{NH} 3}$ and $k_{\mathrm{DS}}$ were estimated by minimizing a least square criterion using the experimental data and are

$$
\mathrm{k}_{\mathrm{s}}=2.5110^{24} \exp \left(\frac{-3.19 \mathrm{eV}}{\mathrm{kT}}\right)\left(\operatorname{Torr}^{-2} \cdot \mathrm{A} \cdot \mathrm{min}^{-1}\right), \mathrm{k}_{\mathrm{DS}}=4.0510^{11} \exp \left(\frac{-1.71 \mathrm{eV}}{\mathrm{kT}}\right)\left(\operatorname{Torr}^{-1}\right)
$$

and $\quad \mathrm{k}_{\mathrm{NH3}}=3.010^{21} \exp \left(\frac{-3.23 \mathrm{eV}}{\mathrm{kT}}\right)\left(\mathrm{Torr}^{-1}\right)$ 
Figure 5 shows a comparison between the experimental deposition rates and the calculated ones along the reactor. As we can see the data agree well. When we process under operating conditions such that the flow rate ratio QNH3/QDS is high (i.e at low $\mathrm{Si}_{2} \mathrm{H}_{6}$ concentration) the product $k_{D S} P_{D S}$ in the denominator term of Eq. (3) is much less than unity so that Eq. (3) could be rewritten as

$$
r_{c}=\frac{k_{s} P_{p s} P_{N H 3}}{1+k_{N H 3} P_{N H 3}}
$$

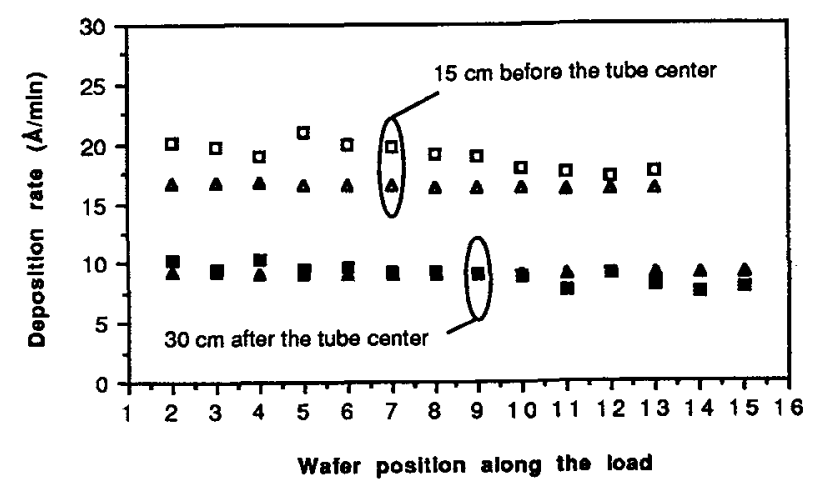

Figure 5: Comparison between the experimental (rexp) and calculated deposition rates (rc) of silicon nitride at the wafer centers for two positions of the load. $\left.\mathrm{T}=600^{\circ} \mathrm{C}, \mathrm{P}=215 \mathrm{mTorr}, \mathrm{QDS}\right)=10 \mathrm{sccm}, \mathrm{Q}\left(\mathrm{NH}_{3}\right)=196 \mathrm{sccm}$.

- $\mathbf{r e x p}$

$\Delta \mathrm{rc}$

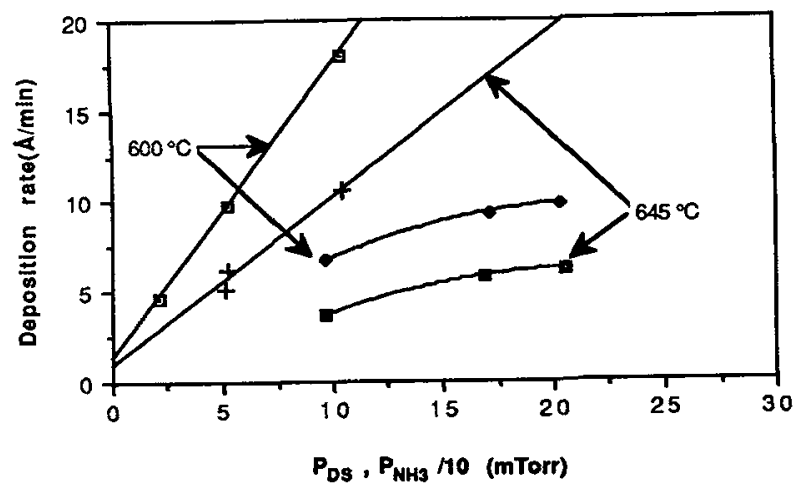

Figure 6: Deposition rate of silicon nitride as a function of disilane and ammonia partial pressures at 600 and $645^{\circ} \mathrm{C}$.

- $+\mathrm{P}_{\mathrm{NH} 3}=205$ mTorr

- $\mathrm{P}_{\mathrm{DS}}=5$ mTorr 
Figure 6 illustrates the deposition rate as a function of the partial pressures of disilane and ammonia when maintaining alternatively constant the partial pressure of one of the gases and varying the one of the other. Both curves reported in Figure 6 are consistent with the mathematical form of Eq. (5).

\section{CONCLUSION}

In this work, the LPCVD of silicon nitride from the $\mathrm{Si}_{2} \mathrm{H}_{6}-\mathrm{NH}_{3}$ and $\mathrm{SiH}_{4}-\mathrm{NH}_{3}$ systems was studied. The addition of ammonia to silane results in the reduction of the deposited layer growth rates, coupled with the inhibition of the silane adsorption by ammonia at the interface.

We also observed a high nonuniformity thickness using the $\mathrm{Si}_{2} \mathrm{H}_{6}-\mathrm{NH}_{3}$ system. This problem is attributed to the dependence of homogeneous disilane decomposition on the total pressure and the increased role of silylene in the surface process. The deposition rate is shown to follow a Langmuir-Hinshelwood model which assumes that the reactants adsorb together but on different active sites on the surface. Thickness uniformities better than $10 \%$ were achieved using a load of wafers of a diameter of $125 \mathrm{~mm}$ and processing under lower pressures.

Concerning the prospective, we have noticed, from the temperature dependence of the film composition versus the flow rate ratio of the reactants in the gas phase, that the $\mathrm{Si}_{2} \mathrm{H}_{6}-\mathrm{NH}_{3}$ system allows the obtaining of nitrogen doped silicon at low temperature (less than $500{ }^{\circ} \mathrm{C}$ ) where homogeneity is easily reached.

Acknowledgements: The authors are indebted to Motorola Inc., L'Air Liquide, the CNET and the Midi-Pyrénées Land Council who supported this work.

\section{REFERENCES}

[1] H. HAYASHI.,T. NOGUSHI and T. OSHIMA.

Jap. J of Appl. Phys. Vol. 23, 11 (1989) pp. L819-L820.

[2] E. SCHEID, L.K. KOUASSI, R.HENDA., J. SAMITIER and J.R MORANTE.

E-MRS Strasbourg (1992), Mater. Sci. Eng., B17 (1993) 185-189.

[3] R. S. ROSLER. Solid state tech. (1977), 20 (4): $63-70$.

[4] M. GuEYE, E. SCHEID, P. TAURINES, P. DUVERNEUIL, D. BIElle-DASPET and J. P. COUDERC, Proc. EuroCVD 8th, Glasgow, September 91,suppl. au Joumal de physique II (1991),Vol. 1 (C2): 63-70.

[5] C.R. KLEIJN. 1991. J. Electrochem. Soc., 138 (7):2190-2200.

[6] E. SCHEID, J.J. PEDROVIEJO, P. DUVERNEUIL, M.GUEYE, J. SAMITIER, A. EL. HASSANI, and D BIELLE-DASPET, E-MRS Strasbourg (1992), Mater. Sci. Eng., B17 (1993) 72-76.

[7] J.-T. WANG, S.-L. ZHANG, Y.-F. WANG, W. ZHANG, Z.-C. CHEN, K.-Y. ZHANG and Y.F. WANG. Journal de physique (1989), 50 (C5): 67-72. 